\title{
HIGHWAY ALIGNMENT ALONG THE CORRIDORS USING REMOTE SENSING AND GEOGRAPHICAL INFORMATION SYSTEM - PERUNDURAI TO PALANI, TAMILNADU, INDIA
}

\author{
S.Loganathan \& Dr. K.Elangovan \\ Assistant Professor, \\ Department of Civil Engineering, \\ Kongu Engineering College, Perundurai, Erode \\ loganathanucs@gmail.com \\ Associate Professor, \\ Department of Civil Engineering, \\ PSG College of Technology, Peelamedu, Coimbatore \\ elangovan2k@hotmail.com
}

\begin{abstract}
Best route location and highway alignment selection process is a complicated one due to many variables it must be considered. Geographic Information Systems (GIS) can easily represent such variables, including topography, environment, built-up areas and geology variables. It is to identify the short route for the vehicles travelling from Perundurai to Palani and to diminish the time journey for the vehicles with possible routes for laying eco-friendly highway. This study took compensation of GIS capabilities that present the ability to overlay maps, merge them and execute spatial analysis on different layers of information in either two or three dimensions. GIS model for route location and highway alignment developed and worn to create alternate highway route applications. After the alternatives are preliminarily deliberated using ArcGIS9.3, the imitation is used to analyze, evaluate and to select the best alternative with least impacts on environment and economy. The selected highway is supposed to connect three districts viz. Erode, Tirupur and Dindugal. In final stages of examination and assessment, the replica envelops the high capabilities in analyzing the impacts of every alternatives, with buffering and spatial relations. Three different routes are identified as left, middle and right routes. Right route is identified as best route which fulfils least cost with eco-friendly environment, material reduction on number of bridges and culverts.
\end{abstract}

\section{Keywords}

RS\&GIS - Highway Alignment - Corridors - Shortest Path - Economic - Maps.

\section{Academic Discipline And Sub-Disciplines}

Civil Engineering, Highway Engineering, Railway Engineering, Traffic Engineering;

\section{SUBJECT CLASSIFICATION}

Highway Engineering ; Horizontal Alignemnt, Vertical Alignemnt, Camber,

\section{TYPE (METHOD/APPROACH)}

Contour, Geomorphology, Drainage, Landuse and Landcover, Soil, Shortest path.

\section{INTRODUCTION}

Optimizing highway new route location for the most economical path is a complex problem that finds the best alternatives for a new highway connecting specified points or locations (Salah et al. 2000). Selecting best route location and highway alignment process is a complex one, due to the numerous variables that must be taken into consideration for achieving the best results using GIS (Emad Basheer Salameh Dawwas et al. 2005). Highway alignment between the two corridors is to provide a better and comfortable path with the identification of the shorter route and for reducing the travel for the vehicles with possible various paths or routes (Loganathan and Elangovan 2013). Highway alignment optimization using GIS with genetic algorithms examines the possessions of various costs on alignment selection and explores optimization in constrained spaces in mountainous terrain regions with very complex geography (Manoj et al. 2004; MinWook Kang et al.2006). Highway network between the new corridors possess multi criteria decision process with the variety of communal, ecological, economic factors and weighted for a large number of corridor alternatives with a new bilevel continuous location model for expansion by adding several corridors within a geographical region (Eusebio Angulo et al. 2014). The draping of road network on triangulated irregular network model as well as on geomorphology map is used to define alternative and efficient route corridors, with exacting emphasis on assortment of the least-cost route and prioritization for repairing (Mahamaya Chattopadhyay et al. 2002). Through spatial operations and database queries, the construction divergence points between the essential coverage and the elected route are recognized and reallocated with GIS (Min-Yuan Cheng and Guey-Lin Chang, 2001). Infrastructure planning of transport according to tradition of public access and needs with environmental impact assessments will leads better highway route for the peoples and stakeholders (Hans Antonson, 2014 ). Use of Analytical Hierarchical Process (AHP) in GIS for route location with thirddimensional data such as vertical slope, earth-volume, size of structure, location and construction expenditure to the independent variables for making the road designs are more scientific (Tae-Ho et al. 2008). Optimization method of 
designers is to minimize the risk associated with restricted sight distance, balance the risk across the two carriageways of the highway and reduce the expected collision frequency by reliability analysis of optimizing the safety in highway crosssections geometric design with standards (Shewkar et al. 2012). A comprehensive approach to the planning of a new alignment is influenced by the location of services, existing road conditions and buildings with the monetary, communal and political costs of land continuation which are recovered through the recent convergence of geospatial imaging, photogrammetry, regional significance examination and alignment optimisation (Peter et al. 2001). Transportation applications by integrating GIS easy to handle and manage spatial and non-spatial data in a wide range for problemsolving and decision-making through monte carlo simulation by comparison of winter maintenance application with positional uncertainties and significant impact (Sungchul Hong et al. 2013). The traffic assignment model with GIS spatial analysis and AutoCAD design capacity is used for integrating the traffic demand analysis and engineering design into a package which optimizes the spatial location and alignment by assembly cost, journey time and ecological load which are integrated into monetary terms and analyzed among the different alternatives for the best option (Zhongzhen Yang et al. 2003). Road mask and road seeds identifies the road network passing through the different elevations with various categories of roads and intersections by high-resolution satellite image as map details -traditionally by surveying-in urban areas as a resource and time consuming in GIS layer (Yongcheol Suh et al. 2003). The representation of road network in the real world using GIS with additional realistic variables such as climate, sight-seeing in sequence, categories of road etc studied with an impedance representation using AHP (Abolghasem et al. 2011). Developed approach of integrating highway design, slope stability and impact on man-made features generates specific environmental and geotechnical criteria for route layout using GIS (Salah Sadeka et al 2000). In order to evaluate better alignment, related data such as topography, soil characteristics, geology, land use and land cover etc are integrated and analyzed (Tae-Ho, Roh et al. 2008) for stable and economic social benefits from Perundurai to Palani.

\section{STUDY AREA}

The highway alignment study area is between the two corridors from Perundurai $\left(11^{\circ} 16^{\prime} 12^{\prime \prime} \mathrm{N}\right.$ and $\left.77^{\circ} 34^{\prime} 48^{\prime \prime E}\right)$ of Erode district to Palani $\left(10^{\circ} 27^{\prime} 01^{\prime \prime} \mathrm{N} 77^{\circ} 30^{\prime} 38^{\prime \prime} \mathrm{E}\right)$ of Dindigual district via Kangeyam and Dharapuram of Tirupur district (Fig. 1). The study area for road alignment project covers the different economic business centre viz., Perudurai SIPCOT, Kangeyam, Dharapuram and Palani. Perundurai is one of the fastest growing commercial centres for turmeric marketing and acting as economic business centre for Erode district and it is located in the National Highways (NH) of 47. Kangeyam is situated adjacent to the city of Tirupur which is an industrial hub for the textile sector and forms one of the most important export centers of India. Tirupur accounts for $90 \%$ of India's cotton knitwear referred to as the textile valley of India. There are about two thousand producing units manufacturing variety of goods such as vests, briefs, panties, tracks, suits etc (Arumugam et al. 2015). Kangeyam is located in the national highways of 67 and connected by different state highways such as SH37, SH81, SH96, SH172 and SH189. Kangeyam is considered as a significant business centre for ghee marketing and Dharapuram is well known business processing for spinning of cotton fabrics, oil processing, bricks manufacturing etc. Dharapuram is strategically located in the line of Palakkad pass from where it gets lot of wind pressure for the plentiful windmills. Amaravathi and Noyyal river, tributaries of Kavery river, crossing the study area. Dharapuram is the major junction point of different highways connecting Tirupur, Pollachi, Erode, Karur, Trichy, Madurai, Theni, Dindigul, Palani and Cochin. Municipality of Palani is one of the most sacred shrines of the Lord Muruga and resorted more than seven million devotees in a year. It is in the backdrop of Western Ghats, Palani hills and Kodaikanal. They are linked by national highway (NH 209). Utilization of preference information, even if preliminary in nature the preference of decision making knowledge has great potential for improving the quality with benefits in technical and methodology in an acceptable level of diversity (Ning Yang et al 2014). At present the highway runoff distances between Perundurai and Palani through Ingur, Chennimalai, Kangayam, Vattamali, Dharapuram and Thoppampatti is $108 \mathrm{~km}$.

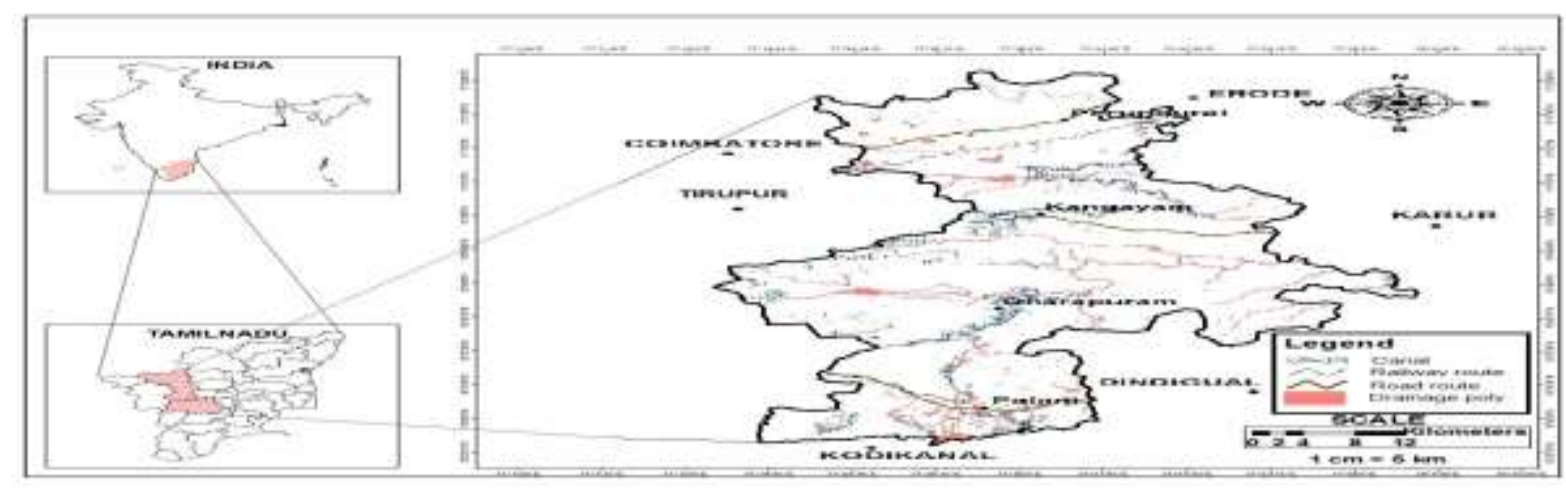

Fig. 1 Location of the study area

\section{METHODOLOGY}

The process for highway alignment selection is a rational one that intends, among other aims, to furnish unbiased information about the effects that the proposed highway will have on the highway environment. The traditional highway selection process is altered in order to reflect the modern industrialized environment using GIS - an integrated model. The model comprises the data collection related to soil, topography, highway network and its design significant of different business activities etc (Fig. 2). The primary function of optimal route selection is to identify the route of small amount 
impedance between two nodes in the road network using ArcGIS functions (Min-Yuan Cheng and Guey-Lin Chang 2001). The objective function and its impedance index are developed for optimization. To select road alignments, it is essential for aligning the traffic flows which run through a road network and to determine the locations of passage points on the way. For determining and evaluating road alignments, evaluation of social, economic and technical factors are considered for improved road alignments. On consternation of social factors, researchers appraises the significance of recovering highway traffic networks in local regions and inspect its social effects on local communities, along with the considerations of further development projects. As for cost-effective factors, it is estimated whether road plans are reasonable with admiration to their speculation issues such as construction and management costs and with respect to economic benefits of investments in those strategies. Technical factors of road plans are separated into traffic-technical and structuretechnical aspects and they are separately examined. While the traffic-technical factors for managing the traffic flow of automobiles, the structure-technical are for adapting natural and structural stabilization. The shortest and the economical path is identified by means of the factors such as landuse, geology, worth of land and soil in GIS tools by assigning weights, ranks of different themes of overlaid maps in most suitable area and for the alignment of new highway route (Subramani and Nandakumar. 2012). Transit demand pattern and policy making of urban planners using oriented selection of bus rapid transit corridor by demographic, transit trip and land use characteristics of the city for effective mass transit (Vimal Gahlot et al. 2012).

Survey of India Toposheets viz. 58E/7, 58E/8, 58E/11, 58E/12, 58E/16, 58F/5, 58F/6, 58F/7, 58F/9, $58 \mathrm{~F} / 10,58 \mathrm{~F} / 11,58 \mathrm{~F} / 13$ and $58 \mathrm{~F} / 14$ (Scale 1:50000) and LISS III satellite imagery are digitized and used for new route location evaluation. Environmental data related to natural reserves, biodiversity, forests, water resources, settlement area etc are accounted and adopted for evaluation of different alternatives.

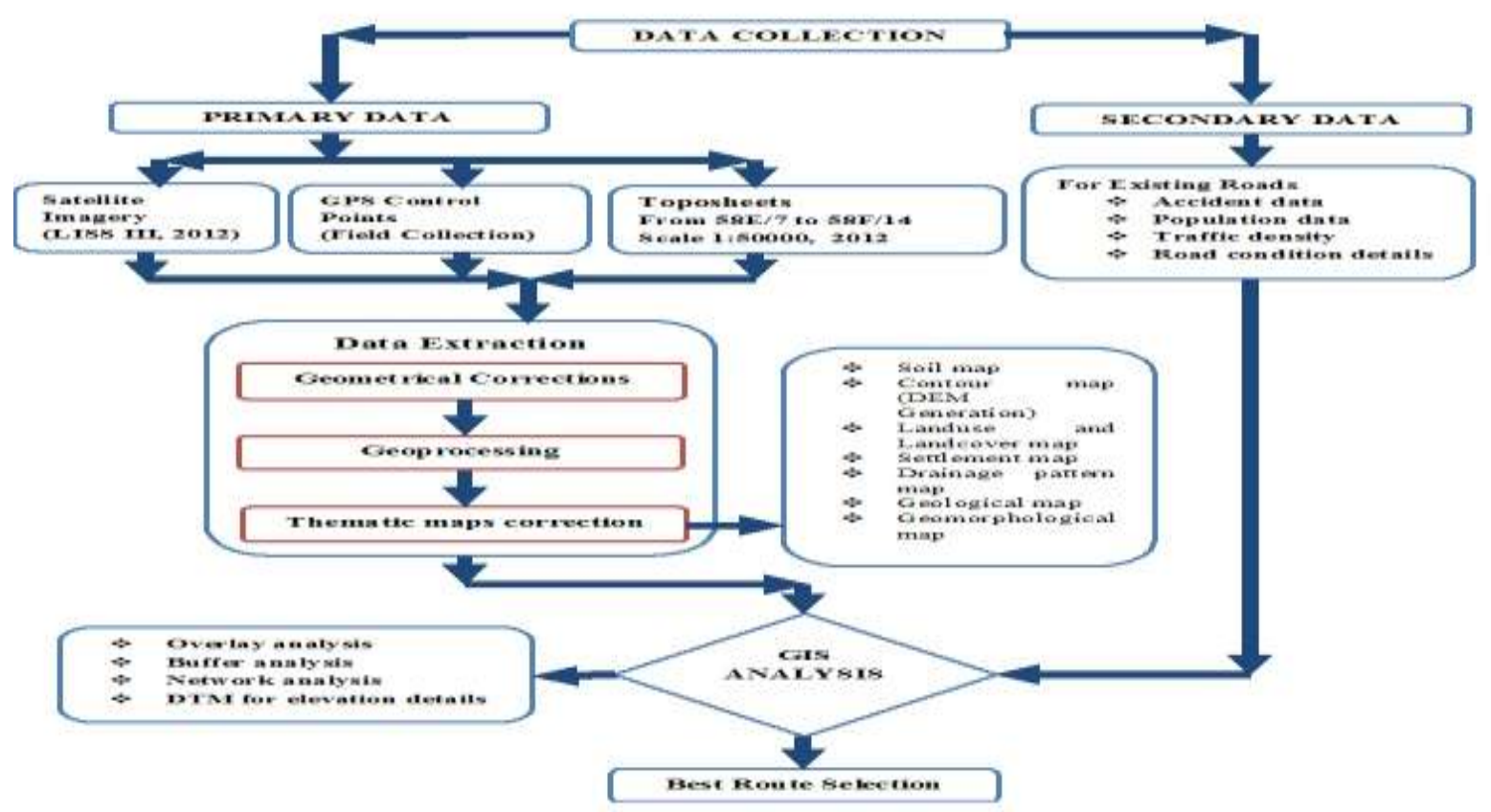

\section{RESULTS AND ANALYSIS}

\section{Data Process and Analysis of Planning}

The steps to discover possible path are outlined below. Corridor is aligned by using ArcGIS9.3 Spatial Analysis Module. Generate source, goal and datasets make different thematic maps based on weight. Performance of weighted distance creates direction and datasets which identifies shortest path. The data process is carried out by chorographic mapping, polygon overlay, contouring, terrain analysis, network analysis, area and length calculations. Terrain modeling of the field according to the contour level using topographic map with standard scale can make less height variation of the road level (Basim et al. 2008). Planning of roads in plain area is somewhat different from hill areas. In hill areas the alignment of roads has to be oblique and is principally governed by the topographical conditions whereas in the plain area the elevation and depressions consideration is basic for alignment during surveying. The elevated regions can be leveled by removing the top surface of the earth which can be used for filling the low lying areas.

Different levels of highway patterns in the study region are national highways $(\mathrm{NH})$ with state highways $(\mathrm{SH})$, major district roads (MDR), other district roads (ODR) and village roads (VR) according to the needs of socio-economic and administrative or strategic consideration based on specifications. The accurate positioning of an object using satellite and applications of technology using GIS leads to easy identification of locations for transportation with lot of benefits as enhanced precision of spatial data, speed of data broadcast, low cost, etc (Mintsis et al 2004). Generally, network of highway paths in the region is multidisciplinary in process such as linking of different economic business centers. 
Topographic and geologic data for the proposed road network area were developed using GIS and used as input to the GIS database. Road network represent the real world using GIS which offers route planning tools in different routes suitable for drivers for easy ridding (Abolghasem Sadeghi-Niaraki et al. 2011). The presence of roads, railways, wetland, forests and drainage features are accounted from the topography based on survey of India.

\section{Contour and Geomorphology analysis}

Contour has been generated by digitizing and rasterizing the topography of the area by using Survey of India map (scale 1:50000). The contour map has been created at intervals of $20 \mathrm{~m}$ for obtaining more accurate information about the field (Fig. 3). Various land features generated and depicted for the road alignment process. Geomorphic units are extracted through digitizing process from the satellites imageries and incorporated into the GIS database (Fig. 4). The most common rock type of the study area comprised by weathered pediplain and followed by pediment-iselberg complex, denudated hills, structural hills at various levels and residual type of hills. The distance visible to the driver is essential for traffic safety due to emergency, overtaking crossings at intersections etc (Maria Castro et al, 2011). As the study corridor is mainly of pepdiplains which are relatively broad and flat rock surface, they are more suitable for laying appropriate highway in the proposed routes.

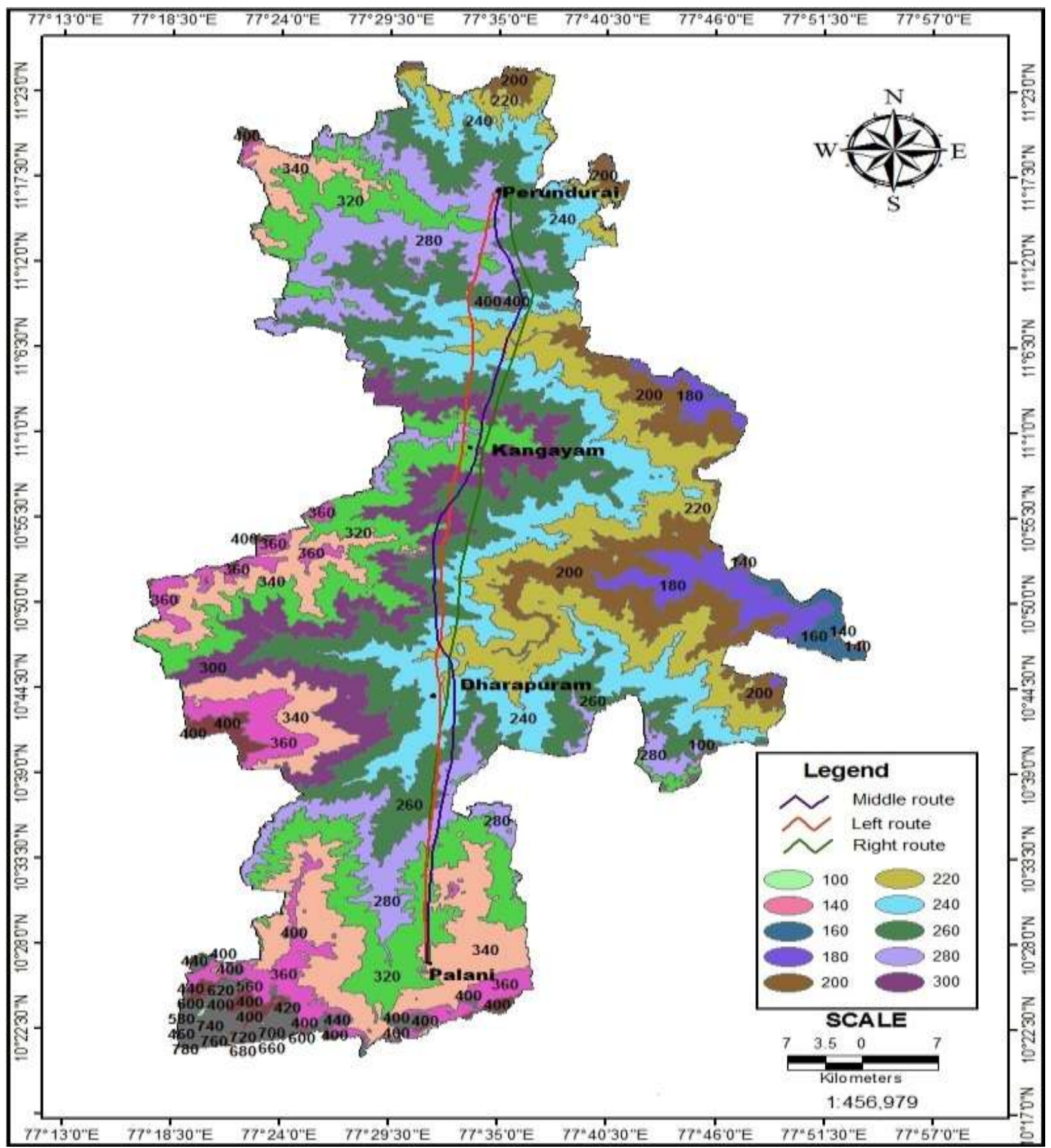

Fig. 3 Contour Map 


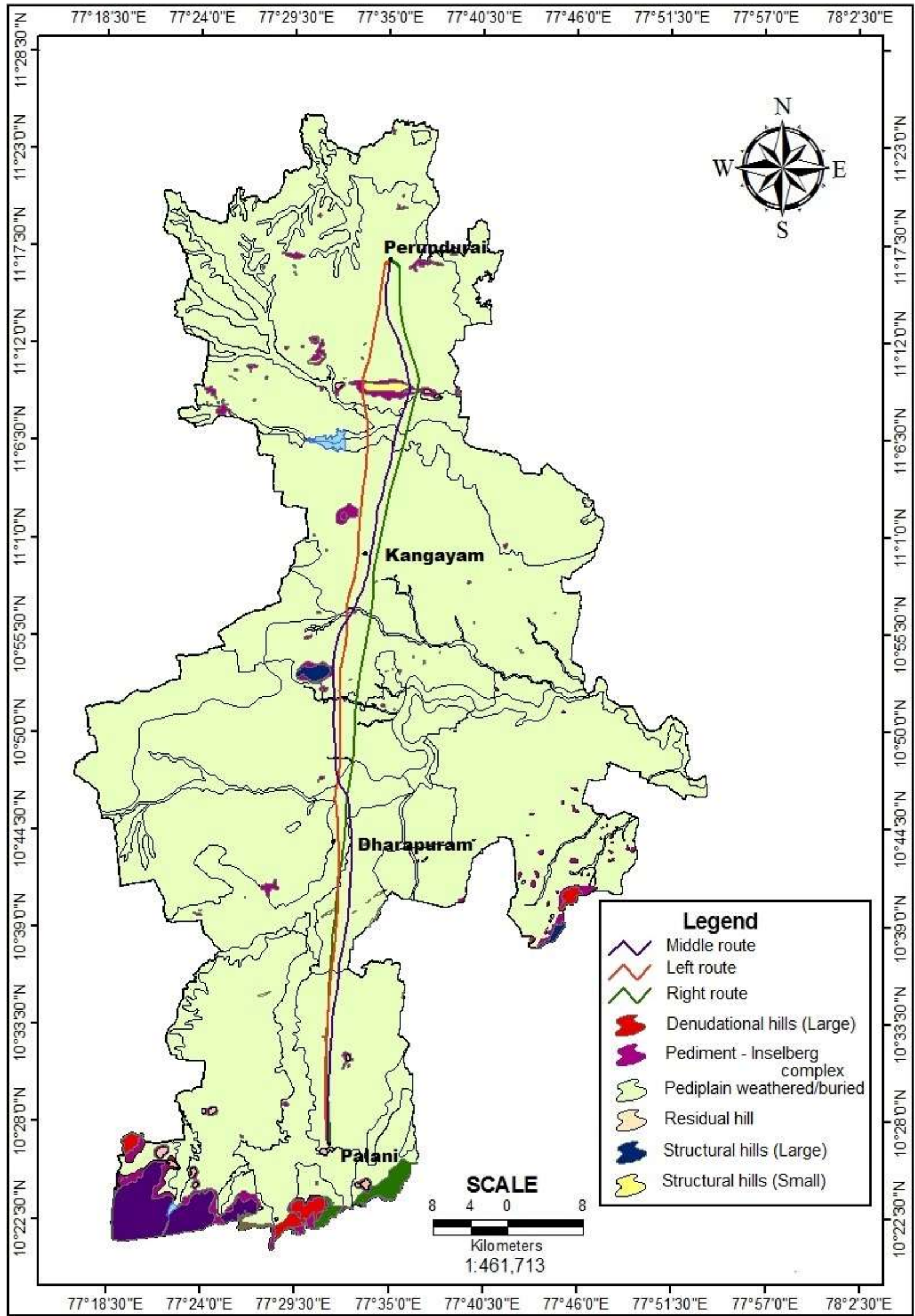

Fig. 4 Geomorphology Map 


\section{Drainage}

The most important hydrological factors which affect the highway route alignment are the surface and sub - surface water conditions, natural streams, irrigation systems of the area etc. Cost-benefit ratio depends upon the complex system of groundwater conditions, types of soils, number of ditches availability, culverts, cuts, cross drainage system, canal - natural streams and irrigation systems such as tanks, reservoirs, lakes or ponds, types and stability of rocks etc. The destructive power of flowing water increases exponentially as its velocity increases. During new road alignment, the natural drainage network should not be affected. Hence, watershed and slope of the study area along with the subsurface conditions are formulated during the alignment of new highway route. The proposed three highway roads are overlaid with the drainage system (Fig. 5). The overlay analysis reveals that the proposed route is having less number of drainage crossing compared to the others. Hence, it proves as a best route by considering the drainage system.

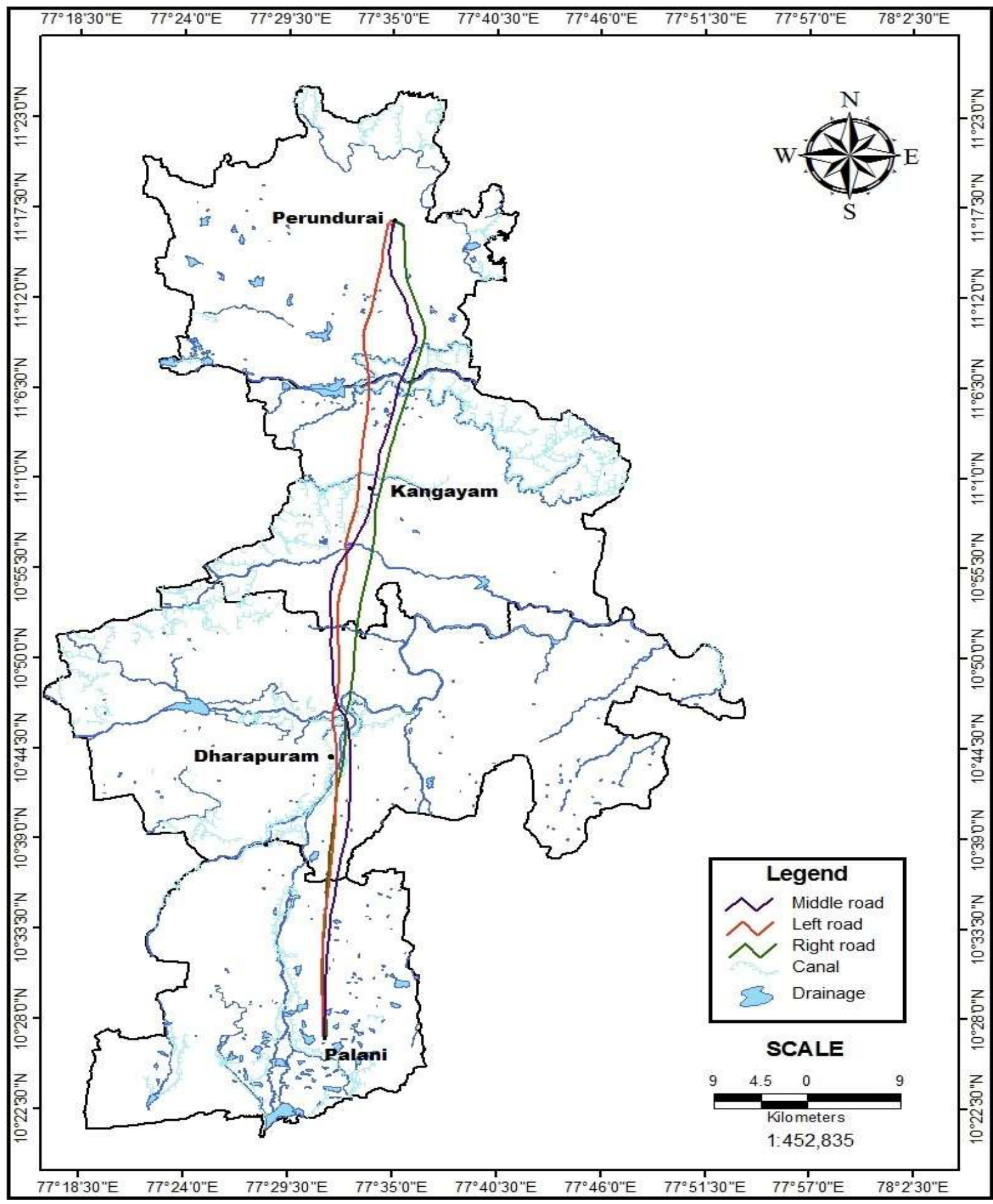

Fig. 5 Drainage map 


\section{Landuse and Landcover}

For the intended field convenience, landuse and landcover are crucial principle for the general coverage of land pattern. The classification of land use/land covers based on supervised classification method in which the entire vicinity falls under categories of agricultural land, build-up area, forest area, waste land and water body. The alignment of highway corridor exploration is based on the enlightenment of landuse and landcover, or else ambiguous of economic worth estimation is inevitable. Urban landscape pattern over a patch density is significantly correlated with road percent coverage and between the corridors in increased habitat of fragmentation by using dataset of landuse and landcover (Ming Zhu et al. 2006). The proposed road alignment area is predominantly covered by the agricultural fields followed by the forest area in the study area (Fig. 6).

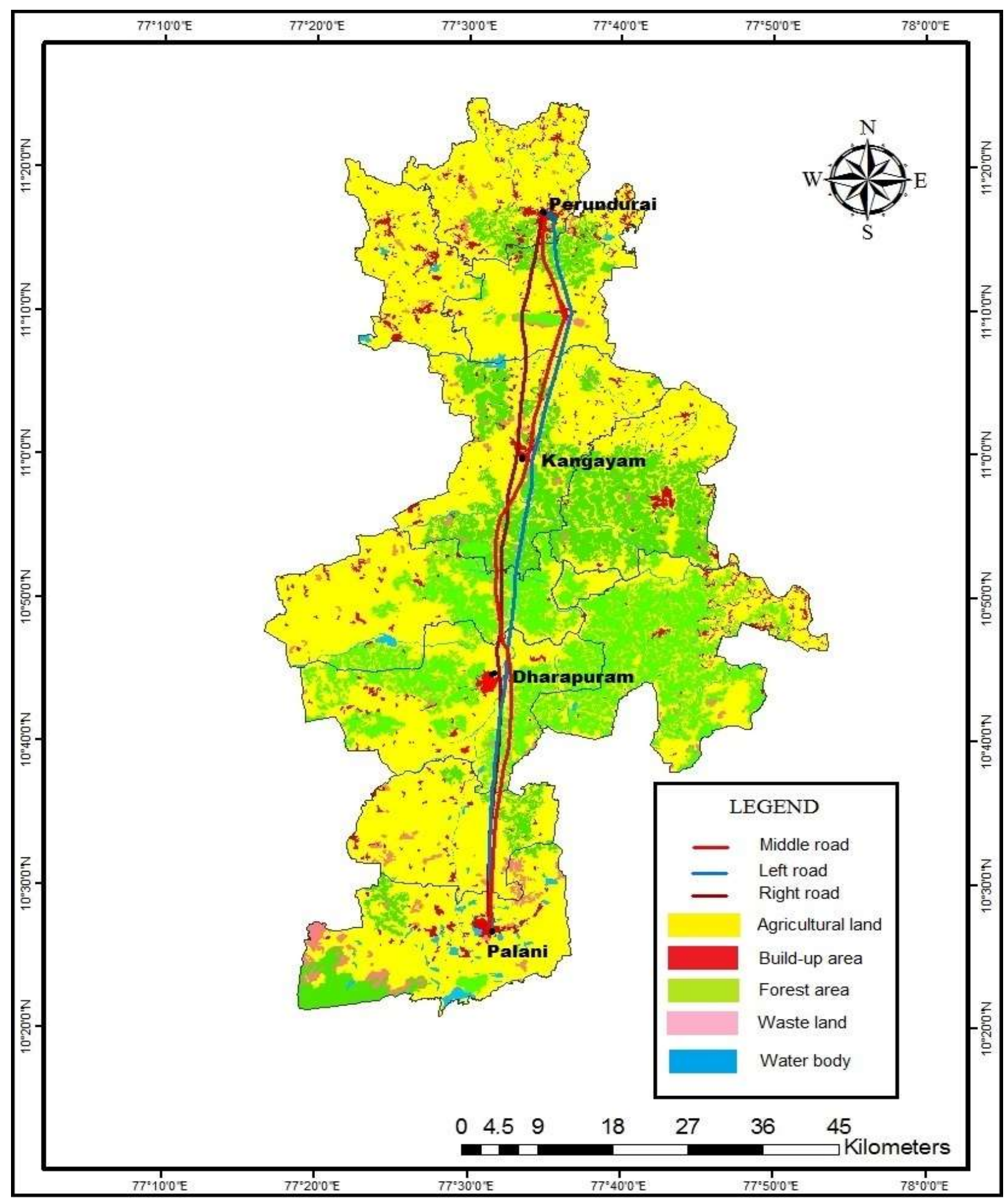

Fig. 6 Landuse and Landcover Map 


\section{Soil}

Background properties of soils such as types and its load bearing capacity for any geographical area provide information about the productive usage of the aerial extension related to soil. Subsoil characteristics depend on the textures of soils. Investigation for the studies such as highway alignment and foundation laying for erection of larger constructions requires a thorough knowledge about the soils in that region. As the area is non homogeneous with soil types, pilot field survey is carried out for analysis and they are classified based on the texture of soil which is composed of sandy clayey loam, sandy clay, clay soil, clayey loam, loamy sand, complex mixtures of sandy loam and smaller amount of other types (Fig. 7).

The three alternative routes are formed as left route, middle route and right route with the distances of $94,93,92 \mathrm{~km}$ respectively (Fig. 8). They are having their own merits on the basis of other factors evaluation. However, the right proposal covers $92 \mathrm{~km}$ which satisfies all the conditions (parameters).

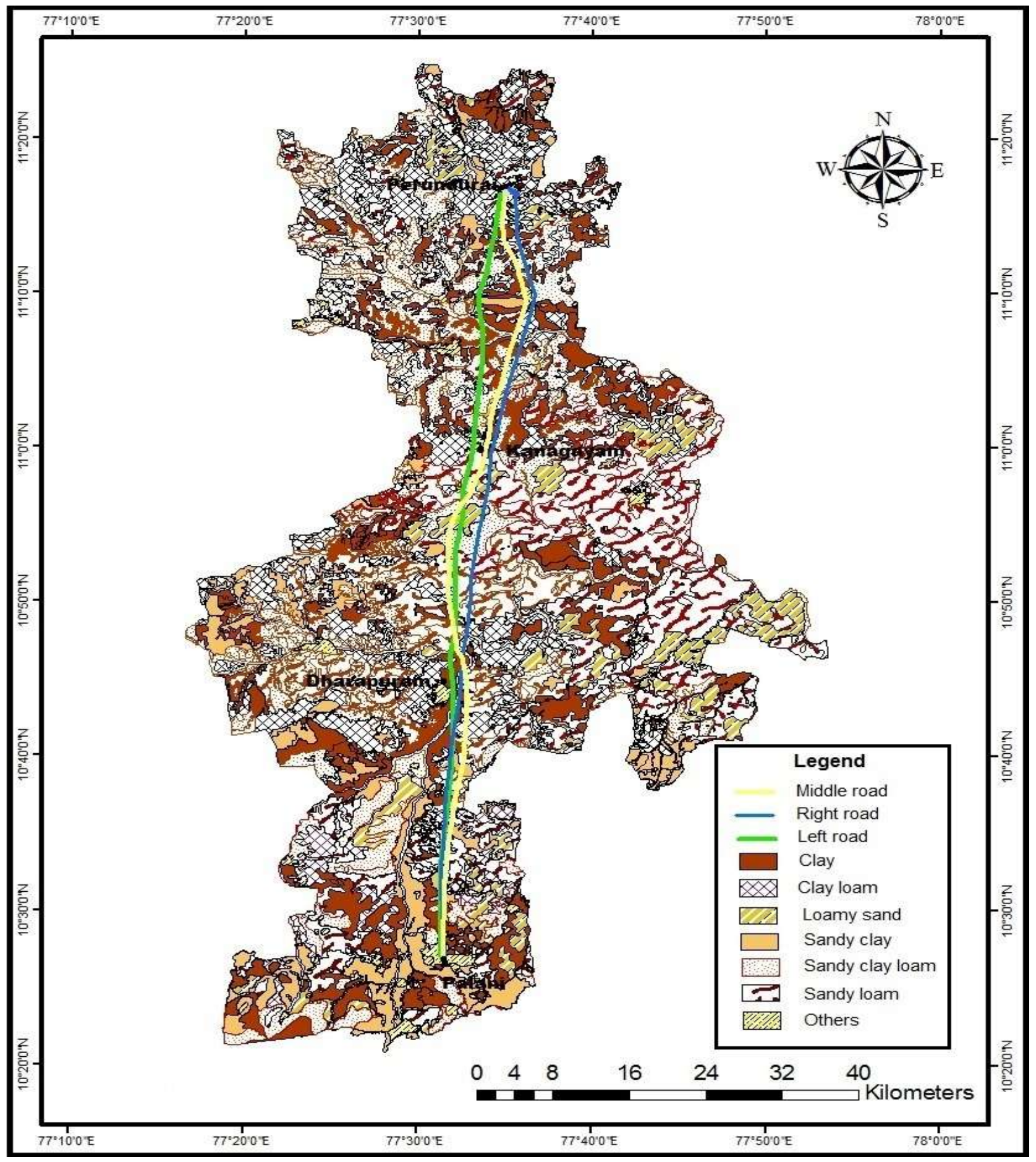

Fig. 7 Soil map of the study area 


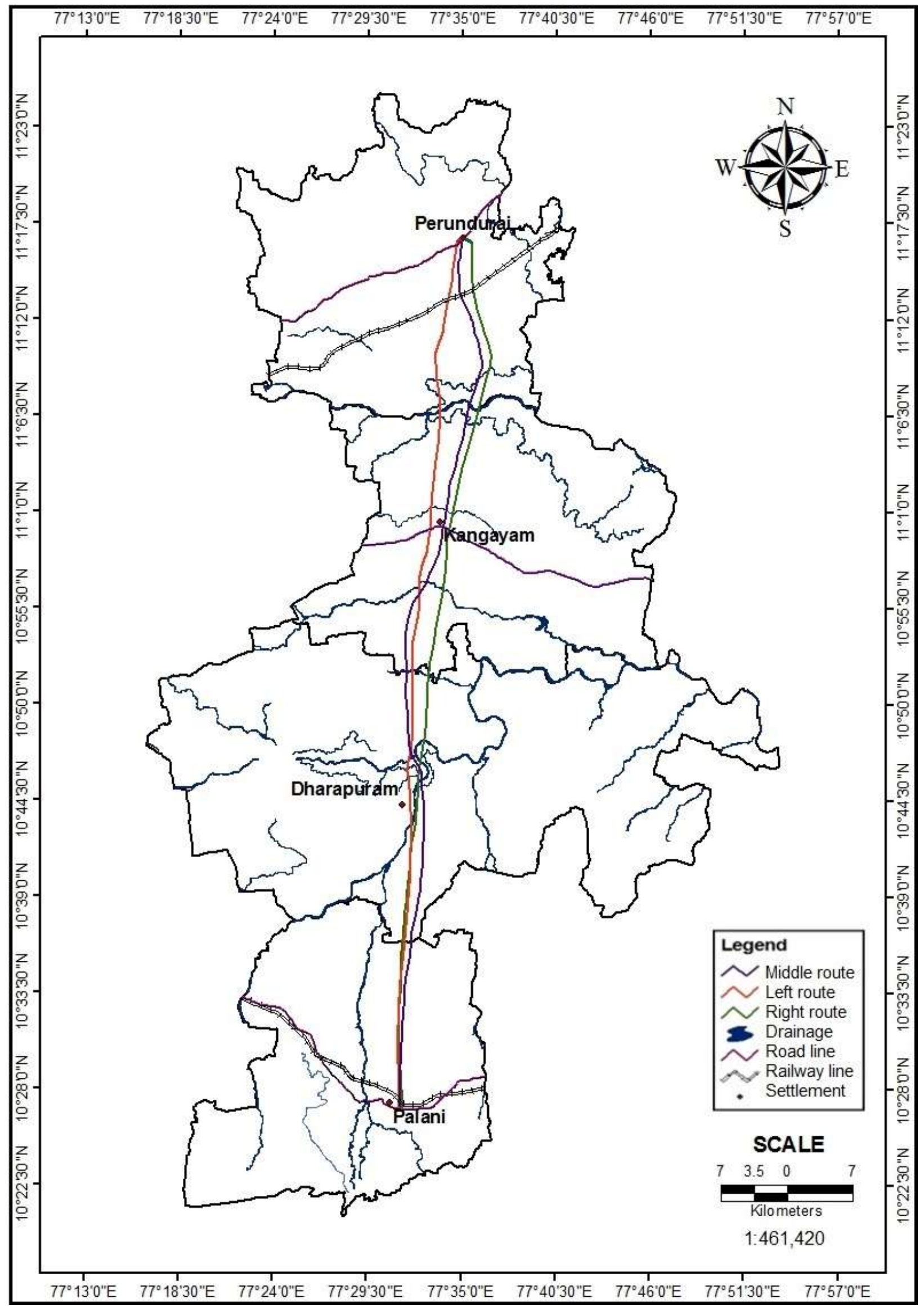

Fig. 8 New alternate locations

\section{CONCLUSION}


Eventhough there are several GIS packages available, no one designed in particular for this application. ArcGIS customized for such application, using external extensions. The investigation designed to use GIS as a tool for new route formation and highway alignment which implies an automated routing system to assist engineers in selecting a best as well as economically worthwhile route from Perundurai to Palani. Three new alternative highway routes are evaluated and identified. The left, middle and right highway routes are with the coverage distances of $94 \mathrm{~km}, 93 \mathrm{~km}$ and $92 \mathrm{~km}$ respectively. The right side route $(92 \mathrm{~km})$ is the best based on cost estimation for implementing the shortest routes for the study area. Hence among the above three alternatives, the right proposal covers $92 \mathrm{~km}$ which satisfies all the conditions. The Expenses made for the alignment on right route will be less compared to others and leads for identification of least path between the corridors.

\section{Acknowledgement}

The author acknowledges Dr. K.Elangovan for guiding and support on identification of new and shortest path using GIS and heartfelt thanks to him for encouraging me to finding out the shortest path in different routes with more coverable areas around the route.

\section{References}

1. Loganathan.S and Elangovan.K, 2013, Application of GIS in highway alignment with soft computing tools, Current Trends in Engineering and Technology (ICCTET), pages 114-119, June 2013.

2. Krao Girish, Sandeep Sarkar and S. Rajagopalan, 2013, Approximating Shortest Path in Large-Scale Road Networks with Turn Prohibitions Using Multi-constrained Path Algorithm, Fifth International Conference on Computational Intelligence, Modelling and Simulation (CIMSim), pages 306 - 311, November 2013.

3. Arumugam.K, Rajesh Kumar.A and Elangovan.K, 2015, Geochemical Process Controlling Groundwater Quality in Avinashi and Tirupur Region, Tamil Nadu, India, International Journal of Applied Environmental Sciences, Vol.10, No.1 pp. 1-13, 2015.

4. Emad Basheer Salameh Dawwas, Sameer A and Abu Eisheh, 2005, GIS as a Tool for Route Location and Highway Alignment, Faculty of Graduate Studies, An-Najah National University, Nablus, Palestine 2005.

5. Juan de Dios Ortúzar and Luis G. Willumsen, 2012, Modelling Transport, IEEE intelligent transportation systems magazine, pages 40 - 41, January 2012.

6. Q. J. Xiang, Y. F. Ma and J. Lu, 2007, Optimal Route Selection in Highway Network Based on Travel Decision Making, Intelligent Vehicle Symposium , pages 1266 - 1270, August 2007.

7. Xiao-Bing Hu Ming-Kong Zhang and Jian-Qin Liao, 2016, A ripple-spreading algorithm to calculate the $k$ shortest paths in a network with time-windows, 12th International Conference on Natural Computation, Fuzzy Systems and Knowledge Discovery (ICNC-FSKD), October 2016, Pages 376 - 382.

8. David Wilkie, Jason Sewall, and Ming C. Lin, 2010, Transforming GIS Data into Functional Road Models for Large-Scale Traffic Simulation, IEEE transactions on visualization and computer graphics, vol. 16, no. 5 , September/October 2010, p 116 - 129

9. Abolghasem Sadeghi-Niaraki, Masood Varshosaz, Kyehyun Kim and Jason J.Jung, 2011, Real world representation of a road network for Transportation Studies, Expert Systems with Applications Vol.38 1199912008, 2011.

10. Basim K. Jrew, Abdul Razzak T. Ziboona and Deleen Mohamed Saleh, 2008, Evaluation of the Use of Remote Sensing Techniques for Highway Alignment Layout, Jordan Journal of Civil Engineering Vol.2, No. 2, 2008.

11. Coray Davis and Manoj K. Jha, 2011, A dynamic modelling approach to investigate impacts to protected and lowincome populations in highway planning, Transportation Research Part A Vol.45, 598-610, 2011.

12. Eusebio Angulo, EnriqueCastillo, RicardoGarcia-Ro denas and Jesus Sanchez-Vizcaino, 2014, A Continous bilevel model for the expansion of highway networks, Elsevier Computers and Operations Research Vol.41, pp.262-276, 2014.

13. Hans Antonson, 2014, Public participation and written submissions: A transport infrastructure planning case study, Transportation Research Part A Vol.70, pp.59-66, 2014.

14. Khanna.S.K, Justo.C.E.G and Veeraragavan. 2014, A, Highway Engineering,10th edn, Nem Chand and Bros., Roorkee, India 2014.

15. Mahamaya Chattopadhyay, Resmi.R.S and Promodhlal.A.S, 2002, Application of Remote Sensing and Geographic Information System in Infrastructure Development, Journal of the Indian Society of Remote Sensing, Vol.30, No. 3, pp.143-147, 2002.

16. Manoj K. Jha and Paul Schonfeld, 2004, A Highway alignment optimization model using geographic information systems, Transportation Research, Part A Vol.38 pp.455-48, 2004.

17. Maria Castro, Luis Iglesias, Jose.A, Sanchez and Luis Ambrosio,2011, Sight distance analysis of highways using GIS tools, Transportation Research Part C Vol.19, pp.997-1005, 2011.

18. Ming Zhu, Jiangang $\mathrm{Xu}$, Nan Jiang, Jianlong Li and Yamin Fan, 2006, Impacts of road corridors on urban landscapr pattern: a gradient analysis with changing grain size in Shanghai, Landscape Ecology, Vol.21, pp.723734, 2006.

19. Mintsis.G, Basbas.S, Papaioannou.P, Taxiltaris.C, and Tziavos.I.N, 2004, Applications of GPS technology in the land transportation system, European Journal of Operational -Research, Vol.152, pp.399-409, 2004.

20. Min-Wook Kang, Manoj K. Jha, Paul Schonfeld, 2012, Applicability of highway alignment optimization models, Transportation Research Research Part C Vol.21, pp.257-286, 2012.

21. Min-Yuan Cheng and Guey-Lin Chang, 2001, Automating utility route design and planning through GIS, Automation in Construction, Vol.10, pp.507-516, 2001. 
22. Ning Yang, Min-Wook Kang, Paul Schonfeld and Manoj K. Jha, 2014, Multi-objective highway alignment optimization incorporating preference information, Transportation Research Part C, Vol.40, pp.36-48, 2014.

23. Peter G. Gipps, Kevin Q. Gu, Alex Held and Guy Barnett, 2001, New technologies for transport route selection, Transportation Research Part C, Vol.9, pp.135 $\pm 154,2001$.

24. Salah Sadekl, Isam Kaysil and Mounia Bedran, 2000, Geotechnical and environmental considerations in highway layouts: an integrated GIS assessment approach, JAG 1 Vol.2, No-3, 2000.

25. Shewkar E. Ibrahim, Tarek Sayed and Karim Ismail, 2012, Methodology for safety optimization of highway crosssections for horizontal curves with restricted sight distance, Accident Analysis and Prevention, Vol.49, pp.476485, 2012.

26. Subramani.T and Nanda Kumar.S, 2012, National Highway Alignment Using GIS, International Journal of Engineering Research and Applications (IJERA), Vol.2, No.4, pp.427-436, 2012.

27. Sungchul Hong, Joon Heo and Alan P. 2013, Vonderohe, Simulation-based approach for uncertainty assessment Integrating GPS and GIS, Transportation Research Part C Vol.36, pp.125-137, 2013.

28. Tae-Ho, Roh, Jong-Chool, Lee, Hee-Gyoo, Kim, Jong-Ju, Kim, Yeoung-Hwa and Jung,2008, Construction on Decision Support System for Route Location Based on GIS, The International Archives of the Photogrammetry, Remote Sensing and Spatial Information Sciences, Vol.37, 2008.

29. Vimal Gahlot, Swami.B.L, Parida.M, and Pawan Kalla, 2012, User oriented planning of bus rapid transit corridor in GIS environment, International Journal of Sustainable Built Environment, Vol.1, pp.102-109, 2012.

30. Vonderohe.A.P, Travis.L, Smith.R.L and Tsai.V, 1993, Adaptation of geographic information systems for transportation, NCHRP Report 359. Transportation Research Board, National Research Council, Washington, DC, pp.77, 1993.

31. Yongcheol Suh, Huijing Zhao, and Ryosuke Shibasaki, 2003, Road Network Extraction from High-Resolution Satellite Image for GIS Applications, KSCE Journal of Civil Engineering, Vol.7, No.5, pp.595-602, 2003.

32. Zhongzhen YANG, Tao FENG and Jia PENG, 2003, Optimizing Highway Alignment in Road Network, Proceedings of the Eastern Asia Society for Transportation Studies, Vol.4, pp.373-380, 2003.

\section{Author' biography with Photo}

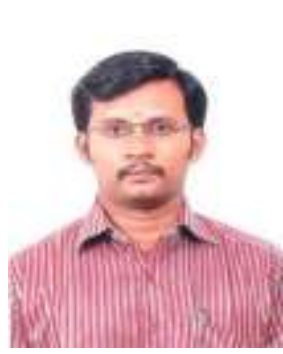

\section{S.Loganathan}

Birth Place is Erode, Tamilnadu, India on 8th November 1984. I had completed UG Civil Engineering in Erode Sengunthar Engineering College on 2007 and PG Infrastructure engineering in PSG College of Technology on 2010 both are affiliated to Anna University Chennai, Tamilnadu India. One Year industrial experience in National Highway Authority of India as a Graduate Trainee in NH-67. Currently working as Assitant Professor in Kongu Engineering College, Perundurai, Erode.

I have Started my carrier Assistant Professor after PG completion and Working Kongu Engineering College, Perundurai, Tamilnadu, India. I have published nine international journals in different part of my research. Loganathan.S having membership in ISTE (Indian Society of Technical Education) and ISRS (Indian Society o Remote Sensing).

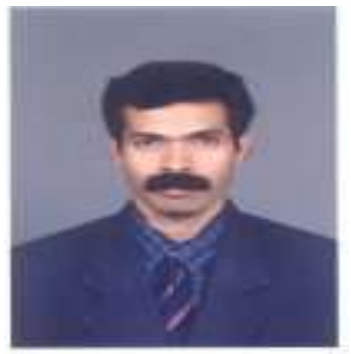

\section{Dr.K. Elangovan}

Birth Place is coimbatore city, He received UG and PG in Bharathiyar University. He got Ph.D in Research of Ground Water Modeling in Bharathyar University.

$\mathrm{He}$ is Working as a Associate Professor in PSG College of Technology. He published book named as Geographic Information System, during 2006 and Sixty six Research papers. Guided Eighty one UG projects and Twenty nine PG projects with his guidance on research Seven persons achieved Ph.D. He is participated in forty three SPD and FDP Training programs. He is Principal Investigator for an AICTE project on Seismic Microzonation of Coimbatore Corporation (Rs. 16.5 Lakhs) sanctioned during 2013 and Three AICTE project handled as Co-Investigator for Rs. 25 Lakhs with One TNSCST student project. He is Coordinator for the National Conference on "Geoinformatics 2000", Three Workshop on GIS as continuing Education Programme One DST PAC Meeting at PSG Tech, Chair person in 5 conferences and Key note Speaker in 2 Conferences. He is reviewer in three Journals and Papers Reviewed 18 research papers for various international journals. He do consultancy in GPS Survey for many organizations. Suitability test for commercial Granites. He is Doctoral Committee Member for 6 Ph D Research scholars and Ph D Thesis Examiner $3 \mathrm{Ph}$ D Research Scholars.

Dr.K. Elangovan Included in Biography of IBC, $A B I$ and Marquis. He is the Life member of various society and Education field such as ISTE, ISRS, IAH, AHI, ISRS, INCA, ISG, IAEM, ISET, FGSI, FMSI, Indian Geotechnical Society, International Association of Hydrologists. 